Article

\title{
Interdisciplinary Cooperative Educational Approaches to Foster Knowledge and Competences for Sustainable Development
}

\author{
Marcel Bassachs ${ }^{1}$, Dolors Cañabate ${ }^{2,3}$, Teresa Serra ${ }^{4}(\mathbb{D})$ and Jordi Colomer ${ }^{3,4, *(D)}$ \\ 1 Department of Pedagogy, University of Girona, 17004 Girona, Spain; marcel.bassachs@udg.edu \\ 2 Department of Specific Didactics, University of Girona, 17004 Girona, Spain; dolors.canyabate@udg.edu \\ 3 Teaching Innovation Networks on Reflective and Cooperative Learning, Institute of Sciences Education, \\ University of Girona, 17003 Girona, Spain \\ 4 Department of Physics, University of Girona, 17003 Girona, Spain; teresa.serra@udg.edu \\ * Correspondence: jordi.colomer@udg.edu; Tel.: +34-630-349-766
}

Received: 15 September 2020; Accepted: 15 October 2020; Published: 18 October 2020

\begin{abstract}
The objective of this paper is to prove that interdisciplinary educational approaches foster knowledge and competences for sustainable development in primary education. The intervention methodology employed is an educational and pedagogical approach to teaching science through physical activities and is based on developing dynamic reflective and cooperative learning environments to strengthen teaching-learning relationships. The educational approach included analyzing students' reflections from their focus groups, in which five categories of cooperative learning: positive interdependence, individual accountability, promotive interaction, the appropriate use of social skills, and group processing, were considered. The results show that, to a significant statistical degree, when the interdisciplinary approaches were adopted the primary school students reached higher levels of understanding, reflective and critical thinking development, and that cooperative learning provided them with a greater perception of sustainable development competences through systems and critical thinking, analysis, interpersonal relationships and collaboration, and strategic action.
\end{abstract}

Keywords: cooperative learning; reflective learning; physical education; sciences; sustainable development; competence; pedagogy; critical thinking

\section{Introduction}

The strategy of the United Nations Economic Commission for Europe postulates that Education for Sustainable Development (ESD) stresses that education systems at all levels, (i.e., primary, secondary and tertiary), be underpinned by and embedded with ethics of solidarity, equality, and mutual respect among people, countries, cultures and generations [1]. The governance of education systems should promote curricula that consider the development of individuals in harmony with nature and that meet the needs of the present generation without compromising the ability of future generations to meet their own needs [2]. The principles for Education for Sustainable Development (ESD) at all levels of education, according to the new 2030 Agenda for Sustainable Development adopted by the world leaders at the United Nations Sustainable Development Summit in 2015 [2,3], urge politicians and policy makers to move society towards a sustainable future. In educational centers, all types of knowledge, skills, and attitudes that foster sustainable development have become the center of attention because ESD is needed for future agents in the field of sustainable development $[4,5]$.

ESD aims to develop the 17 sustainable development goals (SDGs) approved by the United Nations that highlight a global vision for sustainability. Education institutions play a fundamental role 
in empowering individual reflection on one's own actions to foster current and future social, cultural, economic and environmental understanding and impacts [6], to activate participation both locally and globally and to reframe complex situations on a sustainable basis. Individuals are encouraged to reach sustainable development by defining new directions through active participation and societal cooperation [3,7]. Teaching, then, should define, test and assess efficient didactic approaches based on developing the 17 SDGs in all levels of formal education. Teachers should produce class conditions that foster critical thinking to develop the sustainability competence levels of children and young students, and to develop and test activities that assess an individual's sustainable competences and skill acquisition. While there is a long tradition of studies that have investigated pedagogical approaches and their effects on sustainable competences in higher education, in primary education the research, however, it is still considered limited [8].

ESD not only raises awareness of the complexity and dynamism of the issues, it also plays a key role in understanding sustainable development and is applied in a specific way. Education, especially in primary school settings, should aim to incorporate specific sustainable actions in all curricula and should favor developing competences that allow children to think about their actions (in connection with reflective learning) against the background of global challenges and SDGs. The learning and innovative skills proposed by the P21 Framework for 21st Century Learning include creativity and innovation, critical thinking and problem solving, communication and collaboration, and the life and career skills with which to navigate our complex lives. Children, as individuals and as part of society, must also have the power to act in complex situations in a sustainable manner.

Although the use of reflective and cooperative education-focused activities is a significant factor that contributes to optimizing the impact of teaching [8], the use of reflective and cooperative activities has been poorly explored in science, engineering, arts and math education. The impact of combining arts and science education on students' learning is still to be recognized and the way scientific, technological and artistic education is assessed in primary education should be reconsidered. Translating transversal and creative activities from the primary school education domain into a useful form for transferring knowledge to a broader audience is a way of emphasizing greater pedagogical awareness.

Learning promoted through activities designed with cooperation as their basis for scientific and physical education skills and content, is found to develop higher levels of thinking in students. Learning is then considered to take place in a community-centered environment where creative and critical thinking are at the very core of students' development $[9,10]$. However, little is known about the development of science curricula through, for example, physical education or the arts. Teaching sciences in primary school by integrating the arts has provided a platform for primary school students to improve their social and physical skills [11,12], to promote joint thinking and respect for others, as well as provide teachers with a suitable occasion to monitor their students as they endeavor to effectively impart scientific knowledge to their audiences and/or engage an otherwise reluctant individual in the wonders of science. Cooperation within these educational frameworks contributes to promoting the cognitive, socioemotional and behavioral domains of learning in a balanced way [3]. In spite of all these findings concerning cross-discipline approaches promoting creative and critical levels of thinking, little is known about the perception primary school teachers have on the competencies in education that promote creating meaning through cooperative approaches to further operationalize sustainable competences. Therefore, the aim of the study was to closely examine the relationships between cooperative educational approaches for primary school students and promoting education sustainable development (ESD) competences. In addition, we also examined the perceptions primary school students have regarding instructional behavior where creative and critical thinking were promoted. As such, the objective of this study is to explicate the effects the pedagogical intervention had on primary school students' cooperative learning and ESD competences. The influence the interdisciplinary pedagogical approaches have on ESD competences in primary education is yet to be determined. Although some studies have proved that cooperative learning can enhance student reflection [8], little is known about the link between cooperative educational 
approaches and the acquisition of sustainable development competences. To develop such research, primary and secondary school educators would need to provide students with a framework for acquiring sustainable development competences, something which is still a major issue in education.

\section{Theoretical Framework}

The pragmatic notion of reflection was established by distinguishing pedagogical action based on reflective processes from the merely routine action in which any active methodology is taken into consideration [13]. The pedagogical processes that are based on reflection address several principles of critical thinking and analysis and pay particular attention to consciousness and thoughtfulness about one's actions, interdisciplinary work with appreciation, evaluation, contextualization, and use of knowledge and methods from different disciplines, and strategic actions, with development and application of ideas and strategies and ability to reflect on, and deal with, possible risks [5]. Dewey [13] noted that the process of reflection consists of a constructivist model of successive phases in which learners take an active role in finding sustainable solutions to complex problems [5]. Kolb [14] considered that experience is the basis of learning, but learning cannot take place without reflection, which is linked to action. Action, here, may be considered a way to reinforce competences and the principles behind them [15]. Schön [16] described reflective action as a dialogical process between both thinking and doing through the continuous and practical acquisition of competences. Therefore, action is a constructivist process that involves systems and anticipatory thinking, interdisciplinary work and strategic action. Learning in educational contexts should also provide interpersonal relationships and collaboration, empathy and a change of perspective and personal involvement [17,18]. During action, learners (students) ought to go through the entire dialogical cycle several times for any significant and relevant acquisition of competences and to best connect competences and pedagogical approaches for sustainable development [5].

While experimentation in the science, technology, engineering, and math classroom environments is clearly activated in secondary and tertiary education, little is known about primary education. In primary educational systems, knowledge transformation is based on the initial stages of Kolb's model where, while active experimentation is grasped through group experimental processes and interpretative results, there is little appreciation of the intake of competences. In primary education, effective learning environments should be focused on assessment-centered pedagogical approaches in which action should consider unique trajectories to students' learning $[8,19]$. An assessment-centered learning approach should weave formative assessment deeply into the fabric of active experimentation, providing continual, detailed feedback to guide students' learning and instructors' teaching in which sustainability competences are promoted, even at primary school education [19-21].

Cooperative learning focuses on students working together on a project to identify and solve a problem, share ideas or conduct research. It activates skills and understanding in communication and deliberation and peer-to-peer participation to deal with strategic action, as in reflective learning, which is defined as building both sustainable knowledge and skills through interpersonal interactions [22]. It is also reported to promote academic achievement, develop interpersonal skills and relationships, enhance participation through engagement with learning tasks, and improve young people's self-esteem and/or motivation [23]. The modes in cooperative formal science can be used as a tool to stimulate individual students' reflections, especially during the final group reflective process. Cooperative reflection is one of the elements in the reflective process that can be continuously used to aid deliberation [9]. The formal participation of primary students in group discussions also encourages each party to develop personal and individual awareness.

The five variables that mediate the inner mechanisms of cooperative learning are: (i) positive interdependence, (ii) individual accountability, (iii) promotive interaction, (iv) appropriate use of social skills, and (v) group processing [9]. Cooperative learning relies mainly on the complex interdependence between the students. Teachers may facilitate interaction among students by defining open roles for the team members (although these can also be negotiated), and by providing the materials required to deal 
with the problem [24]. As described by Cañabate et al. [24], at the end of the activities proposed by the teacher, the students submit the completed group task and openly discuss the achievement during the final group processing (which corresponds to the last phase of cooperative activities). When comparing cooperative learning with collaborative learning, if cooperative learning is properly guided by the teacher, in the collaborative activity the students themselves can learn to manage the task with no further instruction. In collaborative learning, each student is responsible for their own individual work, i.e., with an initial independence from the other members of the group. Many authors see action in collaborative activities as a broader, more general concept covering multiple approaches to peer collaboration, among which, for example, is cooperative learning $[25,26]$. During cooperative learning, greater involvement and participation of students in their own learning was reported for primary school students, all the while generating spaces for individual and group reflection and fostering greater learning retention. In different physical education contexts and structures, the cooperative learning activities also impact on students' physical competence, cognitive understanding, social skills, and their affective development [27-29]. In this study, activating experimentation in cooperative groups, both in the development of scientific and physical action, is promoted, with the final objective of gaining information on how primary school students reflect on ESD competences during strategic action and systems thinking. As in Lozano et al. [5], competences developed during cooperative learning might be categorized as ESD competences since they foster collaboration and interpersonal relations $[4,5]$.

\section{Materials and Methods}

\subsection{Context}

The Spanish science and physical education curriculum for primary school students centers on basic competences that are developed through various methodological approaches and contents. In Spain, primary school teachers teach almost all the required subjects in the school curriculum. In physical education classes the teachers focus on two core competences: (1) communicating experiences, emotions and ideas using the expressive resources of one's own body, and (2) participating in collective activities of expression and body communication to facilitate relationships with others. Both competences are associated to teaching the following contents: (1) body awareness and control, (2) spatial-temporal orientation, (3) motor coordination, (4) elements and techniques of body expression and communication, (5) appreciation of the resolve to overcome individually and collectively, (6) appreciation of effort and overcoming oneself, (7) cooperation and respect for oneself and others, and (8) execution of different situations that cause coordination of movements, especially laterality, balance and imbalance, and the control of basic motor skills.

In the natural, social and cultural environment knowledge areas, primary school teachers focus on four basic competences: (1) raising research questions on observable characteristics and changes in materials and technological objects, in living things, in nearby ecosystems and on the Earth as a planet; identifying evidence and drawing conclusions that make possible to make decisions to act, and (2) explaining the phenomena with the help of models, verifying the coherence between the observations and the given explanations, and expressing this using communicative channels, (3) fostering finding rational explanations for the facts and problems identified in the environment, and the usefulness of the application of scientific procedures and principles, and (4) participating actively in group work, adopting a responsible, supportive, cooperative and dialogical attitude, arguing one's own opinions and contrasting these with those of others while respecting the basic principles of democratic functioning. These competences are associated with teaching the following contents: (1) observing natural elements and phenomena and communicating these observations through basic forms of representation, (2) communicating observations using different languages, (3) observing and describing interactions that produce changes in a natural system, (4) disassembling and assembling objects and identifying the parts that make them up, (5) analyzing the effects of 
physical variables on objects and materials, and (6) explaining the phenomena (with the help of models), verifying the coherence between the observations and the given application, and expressing this using communicative channels.

When developing teaching approaches and strategies, teachers should assume the role of motivator and facilitator. Taking the planned goals and outcomes into account, teachers help students to establish interpersonal relationships. In the activities the teachers propose, they must welcome the interests and concerns of all the children, listen to each and every one of them, address their contributions and adapt the tasks, i.e., giving them out as required and adjusting the degree of demand and help as needed. Finally, teachers should provide students with proposals for open activities that cater to a diversity of learning profiles.

\subsection{Participants}

The experiment was carried out with ninety primary school students, supervised by three school teachers and the authors of this manuscript. The three school teachers were chosen based on their expertise in reflection learning that they had gained from participating in a project dealing with the interaction of reflective and cooperative learning [8,24]. The sample responded to the objective of the study and, as such, a public school associated to the University of Girona was chosen. Students from the first (mean of 7.4 years old), third (mean of 9.6 years old) and fifth (mean of 10.4 years old) grades participated. A written request was made to the students' families asking for permission to allow their children to participate in the study. This study fully complied with the principles of Regulation (EU) 2016/679 of the European Parliament and of the Council of 27 April 2016 on the protection of natural persons with regard to the processing of personal data and on the free movement of such data. The study research followed appropriate country-specific ethical guidelines and regulations regarding research with minors, including eliciting assent from minors, informed consent from their parents or legal guardians, and storage of protected primary data.

\subsection{Sequential Methodologies and Conceptual Framework}

Initially, the students were presented with, experienced and discussed the basis of the six in-class scientific experiments, then, in the second stage, in a group session the students categorized the main concepts of the scientific experiments with the teacher asking them to answer a group of open questions to promote self-reflection and improve their awareness about effectively communicating science. In stage three, the students translated the scientific categories over to physical categories which, in the fourth stage, were developed cooperatively through dance challenges in small groups. Finally, in groups of five and one teacher, the students participated in an open discussion that reflected on the acquisition of scientific contents, creative developments, cooperative issues and critical thinking. The open discussions lasted for an hour and were recorded. A total of 36 open discussions were recorded, fully transcribed in text and later analyzed for research purposes.

The project's methodology emanates from exploratory activities based on the particular experience of a scientific topic and the reflection through investigation of the categories and paradigms; thus, developing reasoning and explaining frameworks for pragmatic and innovative execution based on movement. This was formulated from the four phases described in Table 1. Based on the dimensions used in research for assessing the cooperative and reflective phases, the method chosen by the students in the reflection process at the end of the phases was considered as being able to be graded by the methodological categorizations. The four above-mentioned phases were also categorized depending on the degree of reflection (Table 1). 
Table 1. Executive phases with sequential implementation of activities with concepts underlying the phases.

\begin{tabular}{|c|c|c|}
\hline Phases & & Activities and the Underlying Concepts \\
\hline \multirow{2}{*}{ Phase 1} & (a) & Experiencing the known (experimenting in cooperation) \\
\hline & (b) & Experiencing the new (the empirical in cooperation) \\
\hline \multirow{3}{*}{ Phase 2} & (c) & Conceptualization based on explicitness (Categories) \\
\hline & (d) & Conceptualization through movement (Categories) \\
\hline & (e) & Conceptualization of theory (Paradigms) \\
\hline \multirow{3}{*}{ Phase 3} & $(\mathrm{f})$ & Functional analysis (Explanation) \\
\hline & (g) & Critical analysis (Critical) \\
\hline & (h) & Reflective analysis (Reflection) \\
\hline \multirow{3}{*}{ Phase 4} & (i) & Apply independently (Self-esteem) \\
\hline & (j) & Apply creatively (Innovation) \\
\hline & $(\mathrm{k})$ & Apply collaboratively (Inclusion). \\
\hline
\end{tabular}

\subsubsection{Scientific Experimentation Phase (Phase 1)}

In Phase 1, each student group was presented with a scientific experiment. Previous to this, the teacher had asked the students to report their prior experience of the content related to the scientific experiment. The six experiments presented to the students, along with the main relevant parameters that define each one, are described in Table 2. In an attempt to activate apprehension, intention, and comprehension [30], each scientific experiment was designed as a student-centered activity consisting of a cooperative teaching approach in which both the scientific experiment and the transfer of the main concepts into cooperative artistic activities were sequenced in time. That is, the scientific experiment activity was organized around a set of six physics experiments and defined the taxonomy of the concepts and topics to be covered. The basis of the approaches were experiments taking place in the classroom in groups of three or as a whole group. In both cases students were asked to work cooperatively. Given that the effectiveness of reflection might strongly depend on the nature of the demonstration, each set of the six experiments was divided into two well-established prior-knowledge sub activities: one to consolidate the recently acquired knowledge through the open group discussion in which students had built up a conceptual map, and the other to introduce the new knowledge produced by each student participating in the experiments themselves (Table 2).

Table 2. Set of six scientific experiments with a list of scientific parameters that constitute the basic contents of the experiments.

\begin{tabular}{cc}
\hline Experiment & Parameters \\
\hline $\begin{array}{c}\text { Exp 1 } \\
\text { The Pendulum } \\
\text { Pendulum waves }\end{array}$ & Longitude, mass, time, rhythm, amplitude, velocity \\
\hline $\begin{array}{c}\text { Exp 2 } \\
\text { Wave motion }\end{array}$ & Longitude, mass, time, amplitude, velocity \\
\hline $\begin{array}{c}\text { Exp 3 } \\
\text { Falling objects }\end{array}$ & Height, mass, time, velocity, gravity \\
\hline $\begin{array}{c}\text { Exp 4 } \\
\text { Rotation }\end{array}$ & Mass, axes, time, angular velocity, radius \\
\hline $\begin{array}{c}\text { Exp } 5 \\
\text { Venturi effect and objects }\end{array}$ & Density, velocity, volume, diameter, pressure \\
\hline $\begin{array}{c}\text { Exp 6 } \\
\text { Inclined plane }\end{array}$ & Longitude, mass, time, velocity, direction, friction, gravity, angle \\
\hline
\end{tabular}

During this phase, the main objective was to encourage the students to describe the immediate environment considering linguistic, corporal-kinesthetic, and artistic expressions. The students explained their prior knowledge involving external objects and the body itself, and its relative position 
in both the in-class and out-of-class environments. The students learned how to deal with both the already-programmed experiments and those that they had to carry out by themselves. In small groups of three or in a whole-class group, students experimented with scientific notions. The students learned through integrated concepts, for example, scientific notions such as distance, speed, volume, density, time, mass, and their variability, continuity and qualities and were able to demonstrate their prior knowledge and link it to the different investigations.

\subsubsection{Conceptualization and Analysis Phase (Phases 2 and 3)}

The trialing of previous knowledge and scientific experimentation led to conceptualization and functional analysis in order to extract categories in relation to science explication and intrinsic movement and also to discussion of the paradigms behind the scientific theories. The students were asked to link scientific dimensions and movement expressions and so they explored the representations of movement through exploration of space such as, for instance, two-dimensional and three-dimensional exploration of geometric shapes, through action, imagination and thought. In addition, through body language and visual language, they explored iconic and symbolic ways of representing the sciences. Likewise, the students explored kinesthetic and musical sensibilities. For example, the oscillation of a pendulum, rhythm and its experimentation in music and math. Finally, through multidimensional communication (individually and collectively) the students explained their practical learning. They were asked to produce individual and small group explanations of the scientific and physical education (movement) concepts and, through active discussion, were able to produce critical and reflective comments. For Experiments 1, 2, 3, 4 and 6, the students explicitly worked on exploring space, time, and spatiotemporal orientation, while for all the experiments, the students explicitly worked on distances, trajectories, velocities, directions, spatial and temporal orientation and their relationships with the others.

\subsubsection{Application Phase (Phase 4)}

In groups of three, the students were asked to elaborate artistic proposals through sensory perception, imagination, experience, reality, ideas, and emotions. Each proposal included movement categories related to the scientific experimentation such as the parameters of physics (speed, time, mass, rotation, distance), along with their variabilities, continuity, and qualities (Table 2). All of the groups were asked to come up with an artistic proposal that was all-inclusive (i.e., all the group members participating on the same level) and creative (each member formulates a unique proposal). Following this strategy, the students explored the abstract representations of scientific structures in small cooperative groups by explicating scientific symbols and concepts and creating artistic experiences which were synergies between the experiments and their interpretation of them through movement. The main objective during this phase was to stimulate individual creation, and to increase students' self-esteem and collective creation as well. Students were able to define the action from the contrast between individual and/or collective experiences.

During Phase 4 , the teachers were conscious of introducing basic competences such as developing interpersonal social skills which included problem solving, decision-making and the capacity to specify and meet mutual objectives. The teachers also promoted positive interdependence as well as individual and group responsibilities. Lastly, in alignment with the national policy requirements in Spain, the teachers fostered mutual respect independent of diverse levels of activity, gender, origin or condition.

\subsection{Data Analysis}

At the very end of the four phases, the students were placed into groups of five and asked to engage in a discussion with a teacher. Three focus groups were established for each session, i.e., a total of 36 focus groups in all. The discussions in which students were asked to produce critical and reflective comments on the whole pedagogical approach lasted for an hour. Two members from the research team participated in the discussion: one directing and guiding it while the other acted as support. The procedure was as follows: a script was prepared by adapting a sequence of questions 
concerning the pedagogical experience each student had had. The group met on the final day after having completed the experience.

The sessions were recorded on video and audio. In the video content analysis, first all content relating to teacher participation (i.e., introduction, introducing open questions and drawing final conclusions) was discarded. Content related to students' comments that were repeated or confused was also discarded. This resulted in a final 6.4-hour video to be considered for analysis. The video was then fully transcribed and 361 units were obtained from the subsequent analysis of the transcription. Analysis was performed in two rounds. In round 1, two researchers from the research team discussed each other's students' comments and reached a consensus on the cooperative and ESD categories for each student's comment. Krippendorff's inter-reliability was 'substantial' for more of the cooperative categories (0.84) and assigned ESD competences (0.78). In round two, all four researchers analyzed the first-round results to come up with a final group category assignment analysis. The inter-reliability was again measured and was in 'almost perfect agreement' for all cooperative components (0.91) and ESD competences (0.96) [31-33].

Units providing information about cooperative learning were classified according to the five dimensions from Johnson and Johnson [9]. Ninety-three units were considered (see examples in Table3). All the units were also analyzed based on the categories of Education for Sustainable Development competences in primary education. To achieve this, a reduced version of the Lozano et al. [5] categories were used to analyze the students' comments. This corresponded to an analysis of 129 units, a portion of which are shown in Table 4. Units were categorized into ten competences: (1) system thinking, (2) interdisciplinary work, (3) anticipatory thinking, (4) justice, responsibility and ethics, (5) critical thinking and analysis, (6) interpersonal relations and collaboration, (7) empathy and change of perspective, (8) strategic action, (9) personal involvement, and 10) tolerance for ambiguity and uncertainty [5].

Table 3. Reported units by students in the five dimensions of cooperative learning.

\begin{tabular}{|c|c|}
\hline Cooperative Learning Dimensions & Unit \\
\hline Positive Interdependence & $\begin{array}{l}\text { - We all kept working together until the very end. } \\
\text { - } \quad \text { We all had fun when we made the turns on ourselves. } \\
\text { - We all did the movements in the different directions, - right, left, } \\
\text { forwards and backwards, really well because we were all focused on } \\
\text { the activity. } \\
\text { - I felt like my classmates really helped me in these activities, something } \\
\text { which doesn't happen in class. } \\
\text { - } \quad \text { I'm really pleased because the others listened to my idea. } \\
\text { - The materials were for everyone and we all shared. } \\
\text { - } \quad \text { We all participated together, and we drew waves with our bodies. } \\
\text { - } \quad \text { All together we did some really fun stuff. }\end{array}$ \\
\hline Promotive interaction & $\begin{array}{l}\text { - } \quad \text { Respect the order of the activity proposed. } \\
\text { It was great to be able to move and I was able to understand the science } \\
\text { experiments so much better. } \\
\text { - } \quad \text { We created movements all together. As if we were the waves in the sea. } \\
\text { - } \quad \text { Pau always asked for help and I always helped him. } \\
\text { - I usually find it really difficult to ask for help when I don't know how } \\
\text { to do something, but in these activities, I did because otherwise we } \\
\text { wouldn't have been about to reach our objective. } \\
\text { Mariona is fantastic, thanks to her constant encouragement we were } \\
\text { able to do... } \\
\text { Usually in class I'm a real chatterbox and I don't listen at all, but this } \\
\text { time I did listen thanks to the help from my group mates who were } \\
\text { always by my side during the activity .... } \\
\text { I'm really pleased because I helped my group to make turns on } \\
\text { different axes. } \\
\text { Not everyone worked on the stuff they had to do, so I had to bring } \\
\text { some order to the group. } \\
\text { My group was always very responsible, and the other groups } \\
\text { congratulated us on that. }\end{array}$ \\
\hline
\end{tabular}


Table 3. Cont.

\begin{tabular}{|c|c|}
\hline Cooperative Learning Dimensions & Unit \\
\hline Individual accountability & $\begin{array}{l}\text { - I don't normally like working in a group, usually I'd much rather work } \\
\text { alone. But in these activities, I had a really good time and I think I } \\
\text { learned better. } \\
\text { - } \quad \text { I always did my bit in all the experiments. } \\
\text { - Luckily most of us paid attention because if not the experiment .... } \\
\text { would never have worked. } \\
\text { - With this kind of hands-on activities, I made more effort and was very } \\
\text { responsible, which I think is thanks to my friends who always helped } \\
\text { me and never let me down. } \\
\text { - I really liked working like this and that's why I made a big effort. } \\
\text { - I don't like to ask questions because I'm really shy, but in the experiment } \\
\text {... I really liked it and I even asked questions so we could do it in } \\
\text { other ways. } \\
\text { I enjoyed explaining one part of the experiment. } \\
\text { In the activity/experiment... I'd have never thought it could be done } \\
\text { like that. }\end{array}$ \\
\hline The appropriate use of social skills & $\begin{array}{l}\text { - Thanks to those who gave me a hand, I was able to rotate on different } \\
\text { planes and axes. } \\
\text { - } \quad \text { I find it really difficult to speak in public. } \\
\text { - } \quad \text { My classmates helped me a lot to make the weird moves. } \\
\text { - } \quad \text { I was very lucky because I had some group mates who are my friends. }\end{array}$ \\
\hline Group processing & $\begin{array}{l}\text { - I think we worked well, but sometimes it all went a bit too fast for me. } \\
\text { - At the end of the session, I loved listening to my classmates explain } \\
\text { how we had done it. } \\
\text { - } \quad \text { Luckily, we could talk and debate, we can't do that in other classes. } \\
\text { - Together we discussed the changes we made to the way we did the } \\
\text { things. Sometimes it was easy to come to an agreement and other times } \\
\text { it was hard. } \\
\text { The diagrams we had at the end of the class helped me a lot to } \\
\text { understand what I didn't have clear. } \\
\text { - Some things went well, other things didn't. } \\
\text { - We didn't argue at all in my group, we all agreed on everything. } \\
\text { - We all did our very best, we couldn't have done more. }\end{array}$ \\
\hline
\end{tabular}

Table 4. Reported units by students in the ten Education for Sustainable Development (ESD) competences.

\begin{tabular}{|c|c|}
\hline ESD Competence & Unit \\
\hline Systems thinking & $\begin{array}{l}\text { - The movement of a ball depends on whether you are on the Earth } \\
\text { or the Moon. } \\
\text { - The wave experiment reminds me of sea waves, which depend on } \\
\text { the strength of the wind. } \\
\text { - An ice skater can spin much faster if she puts her arms really close } \\
\text { to her body }\end{array}$ \\
\hline Interdisciplinary work & $\begin{array}{l}\text { I understand the concepts better when I dance them with my } \\
\text { classmates than when I do it alone. }\end{array}$ \\
\hline Anticipatory thinking & $\begin{array}{l}\text { - I never imagined for a minute you could learn about science } \\
\text { by dancing. } \\
\text { - I learned way more by moving around in class instead of just sitting } \\
\text { in my chair. }\end{array}$ \\
\hline Justice, responsibility and ethics & $\begin{array}{l}\text { - I really like working like this, which is why I made such an effort } \\
\text { to work hard. } \\
\text { I don't usually like to ask questions because I'm really shy but in } \\
\text { the experiment... I liked it a lot and so I asked questions so we } \\
\text { could do it in other ways. }\end{array}$ \\
\hline
\end{tabular}


Table 4. Cont.

\begin{tabular}{|c|c|}
\hline ESD Competence & Unit \\
\hline Critical thinking and analysis & $\begin{array}{l}\text { - When we did those turns on ourselves, we were all so happy } \\
\text { - Now I know that my body is full of axes, and I understand that I } \\
\text { can roll my body in } 5 \text { or } 6 \text { different ways. } \\
\text { - If the Earth had wings, it would also fly! }\end{array}$ \\
\hline $\begin{array}{l}\text { Interpersonal relations and } \\
\text { collaboration }\end{array}$ & $\begin{array}{l}\text { - My group was always very responsible, and the other groups } \\
\text { congratulated us on that. } \\
\text { - At the beginning, early on, it was difficult to decide how to move } \\
\text { in a group but then we began to understand each other and do } \\
\text { more complex exercises. }\end{array}$ \\
\hline $\begin{array}{l}\text { Empathy and change of } \\
\text { perspective }\end{array}$ & $\begin{array}{l}\text { - Sometimes sharing the movement with girls who have come from } \\
\text { far away is more stimulating. } \\
\text { - There are scientific experiments that can be done alone but } \\
\text { sometimes we all need to be there. }\end{array}$ \\
\hline Strategic action & $\begin{array}{l}\text { - Thanks to those who gave me a hand, I was able to rotate on } \\
\text { different planes and axes. } \\
\text { - At the end of the session, I loved listening to my classmates explain } \\
\text { how we had done it. }\end{array}$ \\
\hline Personal involvement & $\begin{array}{l}\text { - In the wave experiment I did more than I had to because it was } \\
\text { so exciting. } \\
\text { - } \quad \text { really enjoy actively participating in all the scientific experiments, } \\
\text { because that way I learn more. }\end{array}$ \\
\hline $\begin{array}{c}\text { Tolerance and ambiguity and } \\
\text { uncertainty }\end{array}$ & $\begin{array}{l}\text { - To do a good movement exercise, first you have to sit down and } \\
\text { talk about what we are going to do. } \\
\text { - } \quad \text { earning the concepts and saying them while we're making concept } \\
\text { maps is really encouraging. } \\
\text { - I wonder if, when I go back to class, I will see science in the } \\
\text { same way. }\end{array}$ \\
\hline
\end{tabular}

\subsection{Data Description and Analysis}

SPSS $21^{\circledR}$ software was used to analyze the data. The database was entered onto a spreadsheet, and subsequently analyzed. The comments obtained from the students were also introduced onto a spreadsheet following a numerical scale and for each type of classification: the degree of reflection, the learning dimensions and ESD competences. The number considered corresponded to the number of comments obtained in each category for each classification. When no comment was made for a certain category, a zero was entered. Data were afterwards tested for homogeneity and normality. Although some of the data sets fulfilled Levene's test for homogeneity, none fulfilled the Shapiro-Wilk test for normality. Because of this, and taking into account that all data sets had 30 observations (i.e., all above five observations), a Kruskal-Wallis test was carried out. Since in all cases the degrees of freedom were $(\mathrm{df}=2)$, the critical $\mathrm{H}$ of Kruskal-Wallis that is expected to result in significant results is for those $\mathrm{H}$ values above 5.991 (the Chi-square for $\mathrm{df}=2$ ). In addition, a post-hoc pairwise comparison between courses was made based on a Mann-Whitney U test.

\section{Results}

The results describe both the qualitative and quantitative primary school students' acquisition of cooperative and sustainable development competences through a self-regulated and continuous exercise of knowledge of scientific and physical education practices. The research involved analyzing both the sustainable development competences (with an emphasis on the capacity of the primary school students to reflect critically), and the capacity of the students to self-regulate the process of cooperation. The whole educational approach was repeated six times to activate deep learning in which the active experimentation and the creation of knowledge were linked to the transformation of 
experiences, beliefs and values. As such, this section first presents the qualitative analysis of knowledge acquisition and the activation of sustainable development, including the dimensional analysis on cooperative learning, and then moves on to the quantitative analysis to discern differences between students in both knowledge and competence acquisitions.

\subsection{Qualitative Analysis}

Table 3 presents the most significant comments extracted from the analysis of the students' reflections and are categorized following the five dimensions of cooperative learning: positive interdependence, individual accountability, promotive interaction, the appropriate use of social skills, and group processing. For the first dimension, positive interdependence, students were aware that cooperation was needed to fulfil the objectives of the activities, and that each member had to participate if the goals were to be achieved. In the promotive interaction dimension, students understood they needed to offer and/or ask for help and that communication with the whole team promoted better conditions in which to complete the activities. Individual accountability was reached when students expressed respect for the other team members, when they were assertive in reporting ideas and when they initiated a process of self-inquiry about the proposed activities. Social skills included accepting feedback from other team members and organizing the roles of the team members. Finally, the group processing dimension could be described in terms of being aware of the processes involved in self-evaluation and the ability to offer opinions on how the group were able to complete an activity or on how the members of the team related to each other.

Table 4 presents the most significant comments extracted from the analysis of the students' reflections and are categorized following the ten ESD competences in accordance with Lozano et al. [6]. The primary school students were able to grasp the principles behind the ESD competencies. They were able to understand complex natural phenomena and the complexity of the body itself, including path dependency and intentionality. Given the educational approach, they were able to reflect on the application of concepts from both science and physical education. In some experiments, students were aware of the dynamics of working on interdisciplinary concepts and cooperating and were conscious of the materials, protocols and dynamics of experimentation. The interdisciplinarity element was achieved as some of the scientific parameters were understood and contextualized in the two disciplines. Some of the students reported principles behind anticipatory thinking - given that they were able to envisage time and spatial scales of knowledge, and also reported the personal changes that had been produced in the self-learning, including a responsibility for one's own actions. As they were encouraged to reflect on practices and opinions, as well as their own values, perceptions, and actions, they also demonstrated critical thinking and analysis abilities. Action was performed mainly cooperatively, which implied having to accept experiences and perspectives from other students' points of view and to be willing and able to act. Finally, students reported a high level of strategic action in the form of developing and applying ideas within the domains, reflecting on interventions and participation and taking responsibility for motivating others.

\subsection{Quantitative Analysis}

The Kruskal-Wallis test for the comparative dimensions of cooperative learning revealed that there were no significant differences between grades for the dimension of positive interdependence, promotive interaction or group processing (Table 5). However, significant differences were found for individual accountability and appropriate use of social skills. The pairwise comparison between courses demonstrated that for individual accountability the differences were significant between the first-year and the third and fifth-year courses but not between the third and fifth-year courses. For appropriate use of social skills, the differences were significant between the first-and fifth-year courses and between the third and fifth-year courses (Table 5). While the first-year students scored higher in promotive interaction, for the third-year students it was individual accountability, and for the fifth-year students positive interdependence, individual accountability, and the appropriate use of social skills (Table 5). 
Table 5. Results corresponding to the Kruskal-Wallis test for the comparative learning dimensions: Positive Interdependence (PoI), Promotive Interaction (PrI), Individual Accountability (IA), Appropriate Use of Social Skills (AUSS) and Group Processing (GP), with the degrees of freedom (df), H-value and $p$-value. Results of the $p$-value for the pairwise comparison between courses for each learning dimension and results for the mean and standard deviation for learning dimension and for each course.

\begin{tabular}{|c|c|c|c|c|c|}
\hline & PoI & PrI & IA & AUSS & GP \\
\hline $\mathrm{df}$ & 2 & 2 & 2 & 2 & 2 \\
\hline H-Kruskal-Wallis & 1.653 & 2.351 & 9.043 & 6.338 & 1.052 \\
\hline$p$-value & 0.438 & 0.309 & 0.011 * & $0.042 *$ & 0.591 \\
\hline \multicolumn{6}{|c|}{ Pairwise Comparison } \\
\hline First-year vs. Third-year & 0.741 & 0.944 & 0.039 * & 0.393 & 0.720 \\
\hline First-year vs. Fifth-year & 0.375 & 0.160 & $0.002 * *$ & $0.020 *$ & 0.522 \\
\hline Third-year vs. Fifth-year & 0.226 & 0.169 & 0.277 & $0.050 *$ & 0.321 \\
\hline \multicolumn{6}{|c|}{ Mean and Standard Deviation } \\
\hline First-year & $0.08 \pm 0.21$ & $0.27 \pm 0.52$ & $0.07 \pm 0.25$ & $0.07 \pm 0.25$ & $0.17 \pm 0.38$ \\
\hline Third-year & $0.17 \pm 0.38$ & $0.23 \pm 0.43$ & $0.27 \pm 0.45$ & $0.13 \pm 0.35$ & $0.13 \pm 0.35$ \\
\hline Fifth-year & $0.30 \pm 0.47$ & $0.10 \pm 0.31$ & $0.40 \pm 0.49$ & $0.33 \pm 0.31$ & $0.23 \pm 0.43$ \\
\hline
\end{tabular}

The Kruskal-Wallis test for the ESD competences revealed that there were significant differences between courses for ESD_5 and ESD_6 (Table 6). However, the pairwise comparison stated that ESD_1 presented significant differences between the first year and fifth-year courses, and also between the third-year and fifth-year courses. For ESD_5, the pairwise comparison showed differences between the first- and third-year courses and between the third- and fifth-year courses. For ESD_6, differences were found only between the first-year and fifth-year. Finally, for ESD-8, the pairwise comparison showed differences between the first-year and fifth-year courses and between the third-year and fifth-year courses (Table 6). In summary, the ESD competences: system thinking, critical thinking and analysis, interpersonal relations and collaboration and strategic action, presented significant differential course differences. The highest mean values were obtained by the fifth-year students in competences ESD_1, ESD_5, ESD_6 and ESD_8 (Table 6).

Table 6. Results corresponding to the Kruskal-Wallis test for the ESD competences: (1) system thinking, (2) interdisciplinary work, (3) anticipatory thinking, (4) justice, responsibility and ethics, (5) critical thinking and analysis, (6) interpersonal relations and collaboration, (7) empathy and change of perspective, (8) strategic action, (9) personal involvement, and (10) tolerance for ambiguity and uncertainty [6], with the degrees of freedom (df), H-value and $p$-value. Results of the $p$-value for the pairwise comparison between courses for each ESD competence and results for the mean and standard deviation for ESD competence and for each course.

\begin{tabular}{|c|c|c|c|c|c|c|c|c|c|}
\hline \multirow[b]{2}{*}{$\begin{array}{c}\text { ESD } \\
\text { Competence }\end{array}$} & \multicolumn{3}{|c|}{$\begin{array}{l}\text { Kruskal-Wallis } \\
\text { Results }\end{array}$} & \multicolumn{3}{|c|}{ Pairwise Comparison } & \multicolumn{3}{|c|}{ Mean and Standard Deviation } \\
\hline & df & H-Kruskal-Wallis & $p$-Value & $\begin{array}{l}\text { First-Year } \\
\text { vs. } \\
\text { Third-Year }\end{array}$ & $\begin{array}{l}\text { First-Year } \\
\text { vs. } \\
\text { Fifth-Year }\end{array}$ & $\begin{array}{l}\text { Third-Year } \\
\text { vs. } \\
\text { Fifth-Year }\end{array}$ & First-Year & Third-Year & Fifth-Year \\
\hline 1 & 2 & 4.402 & 0.111 & 0.522 & $0.050 *$ & $0.048 *$ & $0.17 \pm 0.38$ & $0.23 \pm 0.43$ & $0.53 \pm 0.35$ \\
\hline 2 & 2 & 0.419 & 0.811 & 1.000 & 0.557 & 0.557 & $0.07 \pm 0.25$ & $0.07 \pm 0.25$ & $0.03 \pm 0.18$ \\
\hline 3 & 2 & 0.517 & 0.772 & 0.557 & 0.557 & 1.000 & $0.07 \pm 0.25$ & $0.03 \pm 0.18$ & $0.03 \pm 0.18$ \\
\hline 6 & 2 & 10.854 & $0.004 * *$ & 0.690 & $0.013 *$ & 0.850 & $0.13 \pm 0.35$ & $0.10 \pm 0.31$ & $0.60 \pm 0.86$ \\
\hline 7 & 2 & 1.060 & 0.589 & 0.305 & 0.643 & 0.557 & $0.10 \pm 0.31$ & $0.03 \pm 0.18$ & $0.07 \pm 0.25$ \\
\hline 8 & 2 & 4.878 & 0.087 & 0.954 & 0.042 * & 0.044 * & $0.17 \pm 0.38$ & $0.20 \pm 0.21$ & $0.50 \pm 0.42$ \\
\hline 9 & 2 & 0.733 & 0.693 & 0.643 & 0.690 & 0.393 & $0.10 \pm 0.31$ & $0.07 \pm 0.25$ & $0.13 \pm 0.35$ \\
\hline 10 & 2 & 2.046 & 0.360 & 0.317 & 0.154 & 0.557 & $0.00 \pm 0.00$ & $0.03 \pm 0.18$ & $0.07 \pm 0.25$ \\
\hline
\end{tabular}




\section{Discussion}

\subsection{Cooperative Dimensions for Education in Ssustainability in Primary Education}

Positive interdependence was attained when the children in a group shared a joint goal in which the active, necessary and essential participation of each of the members was needed to achieve it. Our research showed that children in their first year of primary school found it much more difficult to respect and understand this principle since their psychological characteristics were closer to a preoperative stage in which centering and egocentrism are still evident. For them, it was difficult to cede to the other's point of view, and to accept the other team members' contributions to attain a common goal. The third-year students, however, were aware of positive interdependence since they understood needing to be respected and respecting others to reach the objective of the activity. For the fifth-year students, the principles of justice were of great importance since they expressed a higher responsibility for their own actions. For both first and third-year students, simple and straightforward instructions made the goal more attainable since these students were only beginning to participate in active experimentation. Students who work with high interdependence, present more positive attitudes towards teamwork, and more social skills in receiving information and self-assertion.

Promotive interaction was certainly a principle of the utmost importance for first and third-year students. The need for face-to-face social relationships is an intrinsic feature in any child of these ages. Face-to-face interaction for a first- and third-year student is distinguished by a clear and open attitude, regardless of their affinity with the other team members. In contrast, the fifth-year students were more selective and therefore their reflections on the promotive interaction were less assertive. While developing the cooperative practices, the first-year and third-year students participated equally with random team members whereas the fifth-year students experienced tense situations in groups where team members had been randomly selected. This infers that while cooperating, interpersonal relationships should have different modes of communicating action [29], since students expressed a differential skill acquisition in group deliberation, empathizing and collaboration [29]. In primary schools, the social benefits of collaborative learning are a separate outcome of group work, rather than being either a pre-condition for or a direct consequence of successful activity, therefore indicating that positive interdependence and promotive interaction can promote sustainable competences in terms of emphasizing interpersonal relationships from active participation in community processes [34].

While any primary school student was able to respond to their individual responsibility, the perception first-year students have about responsibility is low since they manifested some impulsivity (vestiges of centering and egocentrism) with them trying to monopolize, intervene, and interfere in the tasks of the other team members. That is, the members of the group themselves were prone to controlling the rest to maintain the roles of each participant. Therefore, cooperative practices should be aware of the students' internal regulations. In the case of the third and fifth-year students, individual participation through taking responsibility for oneself and for motivating others was greater. Because their internal control was better, fewer rules had to be set by the teachers. Moreover, the willingness to act was highly accepted, with higher levels of participation in the cooperative groups. For the fifth-year students, reflecting on their own actions was highly related to accepting and embracing not only new paradigms in the sciences, but also one's own values, perceptions and actions. Group goals may motivate students to take responsibility for one another independent of the teacher, providing increased opportunities for cognitively appropriate learning activities. This is a general issue since individual responsibility is linked to ESD competences through the attentive enhancement of emotional intelligence [35-38].

Clearly, cooperative learning was an excellent learning approach to develop social and interpersonal skills. Participatory and cooperative approaches enhanced social relations that then boosted the individuals' inner desire to participate in any activity in the group, as well as fostering discussion and confrontation between equals, and the personal involvement of the students. Again, for the first-year students, the perspective was still rather self-centered, impulsive and based on their 
own experience (focus). For these students, the teacher had to create a framework of group participation recommendations in relation to respect. Therefore, a normative framework should be visible when facing a confrontation of ideas, participating in a discussion, reflection, etc. For higher level students, this principle was easier to develop if enough time for description and argumentation was provided as their reflective capacity and emotional distancing were already much more present, with the students even reaching the stage of appropriating information within formal operations. Finally, the ability to reflect on the group's own functioning, and therefore on their possible actions for its improvement, was a much more plausible feature for the fifth-year students. For the first-year students, who were still struggling with the process of reversibility, reflecting on the process of the operation of the group was still a retrospective reflection. Therefore, the principle of reflection underlying the competence of critical thinking and analysis was more readily attained by the older students. The importance of applying and respecting this principle in the processes of cooperative learning relied on establishing guidelines and providing guidance and moments for the personal and group self-evaluation process. The inference of the teacher in guiding this process, for instance by establishing instruments such as rubrics of a more visual nature, could allow this age group to process ESD competences dynamically [8]. The transition towards sustainability is reported as recalling action and understanding the complexities that arise within an interconnected system, as well as the ability to collaborate with people from diverse backgrounds, while keeping an eye on the future [39].

\subsection{Competence for Sustainable Development in Primary Education}

The model of the dimensions of controlled experiments offered by the educational approach promoted the acquisition of a set of ESD competences, as well as knowledge of scientific and physical parameters and their interaction with the physical world. It also entailed the acquisition of specific motor skills. Therefore, this study has been able to verify that an approach using a cross-correlation of education areas, that is, the experimentation of scientific concepts through movement, allowed for individual intake of ESD competences. The analysis of the experiences carried out in the classroom identified a set of activities and results that can be divided into four methodological sections summarized as: (1) scientific experimentation, (2) conceptualization and functional analysis, (3) scientific application, and (4) critical and reflective transformation, which were set up to foster ten ESD competences: systems thinking, interdisciplinary work, anticipatory thinking, justice, responsibility and ethics, critical thinking and analysis, interpersonal relations and collaboration, empathy and change of perspective, strategic action, personal involvement and finally, tolerance and ambiguity and uncertainty [5]. Among these competences, primary school students' perceptions were higher for systems thinking, critical thinking and analysis, interpersonal relations and collaboration and strategic action.

The group of activities proposed within the interdisciplinary approach for learning science through movement and promoting ESD competences was based on developing two main axes. The first being continuous perception, which is based on experimentation through observation and through the body and is made explicit through concrete experiences and the conceptualization of scientific terms, phrases of movement and cognitive assimilation of concepts and structures. This axis is directly linked to the ESD competences of systems thinking and strategic action through the principles of understanding complex phenomena, connectivity and cause-effect relationships, the development of ideas and strategies, the ability to implement interventions, the scope of creativity and participation and taking responsibility for motivating oneself and others. The second axis is continuous processing which is based on continuous experimentation and reflecting on content and process, one's values, perceptions, and actions, learning from other perspectives and initiating one's own learning [5].

The cyclic learning process also aimed at developing actions related to increasing intrapersonal skills, reformulating beliefs and being aware of attitudes towards active scientific experimentation and towards relationships when cooperating [8]. The assessment was carried out by achieving initial, formative and summative objectives using various instruments, including systematic observation during the learning process, and by analyzing advances in progress, (for example, in aspects of 
expressive motor skills: making movements and their precision) thus exploring the fundamental dimensions of movement/dance: space, energy, time, etc. To reach educational processes that promote creativity and critical thinking through action and reflection for primary students, divergent (not convergent) attitudes must be promoted [8,24]. Divergent attitudes tend to search for all possible solutions (multiplicity of original responses) in the quest for a conformist solution. To do this, ESD competences in primary education need to be addressed from an integral and integrating perspective [38]. This implies promoting the development and autonomy of students and stimulating and fostering critical reflection and analysis, as well as self-criticism. When learning is active, grounded and situated, it encourages students to innovate, and therefore activates the development of students' personalities and prepares them for their social, cultural and sustainable development.

\section{Limitations of the Study}

Future studies on cooperative learning and associated competences should provide the individual student's level and degree of achievement in relation to the competencies related to sustainability. The information on students' competences is scarcely measured since the educational approaches that deal with cooperative learning must incorporate its analysis with almost no reported rubrics of analysis. That is to say, in the same way that in the primary education curriculum each educational domain presents indicators of evaluation that are intimately related with the development of learning outcomes, it would also be necessary to elaborate evaluation indicators in relation to the development of sustainable competences. Developing learning outcomes according to the sustainability competences for each course will facilitate the learning process [40], while allowing teachers to guide their teaching with new strategies, methodologies and learning activities that suit each of the primary courses/cycles. Therefore, one of the limitations of this study is knowing, in relation to the competences of sustainability, the level and degree of development of each of the students who have participated in it.

The influence of different pedagogical approaches on competences is to be yet determined, especially in primary and secondary school contexts. Although we have tested how cooperative learning can enhance student reflection on the acquisition of sustainable development competences, more studies should be undertaken to determine the efficacy the pedagogies have on the competences. However, to develop such research, educators in primary and secondary schools would need to provide students with a framework for acquiring competences for sustainable development-which is a major issue in education.

Author Contributions: Conceptualization, M.B. and J.C.; methodology, M.B. and T.S.; validation, M.B., T.S. and D.C.; formal analysis, M.B. and J.C.; investigation, M.B. and J.C.; resources, J.C.; data curation, M.B. and J.C; writing—original draft preparation, M.B.; writing—review and editing, M.B. and J.C.; visualization, M.B. and J.C.; supervision, J.C.; project administration, J.C.; funding acquisition, M.B. and J.C. All authors have read and agreed to the published version of the manuscript.

Funding: This research was funded by FECYT, Spanish Federation for Sciences and Technology, grant number FCT-15-10017" and by the Institute of Sciences Education Josep Pallach, University of Girona, grant number ICE-XIDAC03-2020.

Acknowledgments: The authors are very grateful to the Department of Physics, University of Girona, for providing the know-how and material to set-up the scientific experiments in the primary schools.

Conflicts of Interest: The authors declare no conflict of interest.

\section{References}

1. UNECE. Empowering Educators for a Sustainable Future: Tools for Policy and Practice Workshops on Competences in Education for Sustainable Development UNESCO (2005); United Nations EC/CEP/: New York, NY, USA, 2013; Volume 165, pp. 14-15.

2. UN. Agenda for Sustainable Development. In Resolution Adopted by the General Assembly on 25 September 2015 (A/70/L.1); UN: New York, NY, USA, 2015.

3. Cebrián, G.; Junyent, M.; Mulà, I. Competencies in Education for Sustainable Development: Emerging Teaching and Research Developments. Sustainability 2020, 12, 579. [CrossRef] 
4. Rieckmann, M. Chapter 2-Learning to transform the world: Key competencies in ESD. In Issues and Trends in Education for Sustainable Development; Leicht, A., Heiss, J., Byun, W.J., Eds.; UNESCO: Paris, France, 2018; pp. 39-59. Available online: http://unesdoc.unesco.org/images/0026/002614/261445E.pdf (accessed on 1 September 2020).

5. Lozano, R.; Merrill, M.Y.; Sammalisto, K.; Ceulemans, K.; Lozano, F.J. Connecting Competences and Pedagogical Approaches for Sustainable Development in Higher Education: A Literature Review and Framework Proposal. Sustainability 2017, 9, 1889. [CrossRef]

6. Barth, M.; Godemann, J.; Rieckmann, M.; Stoltenberg, U. Developing key competencies for sustainable development in higher education. Int. J. Sustain. High. Educ. 2007, 8, 416. [CrossRef]

7. UNESCO. Road Map for Arts Education. In Proceedings of the World Conference on Arts Education: Building Creative Capacities for the 21st Century, Lisbon, Portugal, 6-9 March 2006.

8. Colomer, J.; Serra, L.; Cañabate, D.; Serra, T. Evaluating knowledge and assessment-centered reflective-based learning approaches. Sustainability 2018, 10, 3122. [CrossRef]

9. Johnson, D.W.; Johnson, R.T. An educational psychology success story: Social interdependence theory and cooperative learning. Educ. Res. 2009, 38, 365. [CrossRef]

10. Dumitru, D. Creating meaning. The importance of Arts, Humanities and Culture for critical thinking development. Stud. High. Educ. 2019, 44, 870. [CrossRef]

11. Cañabate, D.; Colomer, J.; Olivera, J. Movement: A language for growing. Apunt. Educ. Física Y Deportes 2018, 134, 146-155. [CrossRef]

12. Torrents, C.; Castañer, M.; Dinušová, M.; Anguera, M.T. Dance divergently in physical education: Teaching using open-ended questions, metaphors, and models. Res. Dance Educ. 2012, 2, 104-119. [CrossRef]

13. Dewey, J. How We Think; Prometheus Books: Buffalo, NY, USA, 1933.

14. Kolb, D.A. Experiential Learning: Experience as the Source of Learning and Development; Prentice Hall: Englewood Cliffs, NJ, USA, 1984.

15. Kolb, A.Y.; Kolb, D.A. Learning Styles and Learning Spaces: Enhancing Experiential Learning in Higher Education. Acad. Manag. Learn. Educ. 2005, 4, 193-212. [CrossRef]

16. Schön, D. The Reflective Practitioner: How Professionals Think in Action; Basic Books: New York, NY, USA, 1983.

17. Cañabate, D.; Nogué, L.; Serra, T.; Colomer, J. Supportive peer feedback in tertiary education: Analysis of pre-service teachers' perceptions. Educ. Sci. 2019, 9, 280. [CrossRef]

18. Ayllón, S.; Alsina, Á.; Colomer, J. Teachers 'involvement and students' self-efficacy: Keys to achievement in higher education. PLoS ONE 2019, 14, e0216865. [CrossRef] [PubMed]

19. Beatty, I.D.; Gerace, W.J. Technology-enhanced formative assessment: A research-based pedagogy for teaching science with classroom response technology. J. Sci. Educ. Technol. 2009, 18, 146-162. [CrossRef]

20. Cowie, B.; Bell, B. A model of formative assessment in science education. Assess. Educ. Princ. Policy Pract. 1999, 6, 101-116. [CrossRef]

21. Heemsoth, T.; Heinze, T. Secondary school students learning from reflections on the rationale behind self-made errors: A field experiment. J. Exp. Educ. 2016, 84, 98-118. [CrossRef]

22. Colomer, J.; Serra, T.; Cañabate, D.; Bubnys, R. Reflective learning in higher education: Active methodologies for transformative practices. Sustainability 2020, 12, 3827. [CrossRef]

23. Casey, A.; Goodyear, V.A. Can cooperative learning achieve the four learning outcomes of physical education? A review of literature. Quest 2015, 67, 56. [CrossRef]

24. Cañabate, D.; Serra, T.; Bubnys, R.; Colomer, J. Pre-service teachers' reflections on cooperative learning: Instructional approaches and identity construction. Sustainability 2019, 21, 5970. [CrossRef]

25. Hatami, A. The effect of collaborative learning and self-assessment on regulation. Educ. Res. Rev. 2015, 10, 2164-2167. [CrossRef]

26. Page, A. Implementing cooperative learning: A consideration of barriers and enablers. J. Initial Teach. Inq. 2017, 3, 49-52. [CrossRef]

27. Goodyear, V.A.; Casey, A. Innovation with change: Developing a community of practice to help teachers move beyond the 'honeymoon' of pedagogical renovation. Phys. Educ. Sport Pedagog. 2013, 20, 186-203. [CrossRef]

28. Casey, A.; Dyson, B.; Campbell, A. Action research in physical education: Focusing beyond myself through cooperative learning. Educ. Action Res. 2009, 17, 407-423. [CrossRef] 
29. Morgan, K. Applying mastery TARGET structures to cooperative learning in physical education. J. Phys. Educ. Recreat. Dance 2019, 90, 27-32. [CrossRef]

30. Abdulwahed, M.; Nagy, Z.K. Applying Kolb's experiential learning cycle for laboratory education. J. Eng. Educ. 2009, 98, 283-294. [CrossRef]

31. Chamoso, J.M.; Cáceres, M.J. Analysis of the reflections of student-teachers of mathematics when working with learning portfolios in Spanish university classrooms. Teach. Teach. Educ. 2009, 25, 198-206. [CrossRef]

32. Kember, D.; McKay, J.; Sinclair, K.; Wong, F.K.Y. A four-category scheme for coding and assessing the level of reflection in written work. Assess. Eval. High. Educ. 2008, 33, 369-379. [CrossRef]

33. Krippendorff, K. Computing Krippendorff's Alpha-Reliability. 2011. Available online: https://repository. upenn.edu/asc_papers/43 (accessed on 21 September 2020).

34. Tolmie, A.K.; Topping, K.J.; Christie, D.; Donaldson, C.; Howe, C.; Jessiman, E.; Livingston, K.; Thurston, A. Social effects of collaborative learning in primary schools. Learn. Instr. 2010, 20, 177-191. [CrossRef]

35. Lambrechts, W.; Mulà, I.; Ceulemans, K.; Molderez, I.; Gaeremynck, V. The integration of competences for sustainable development in higher education: An analysis of bachelor programs in management. J. Clean. Prod. 2013, 48, 65-73. [CrossRef]

36. Slavin, R.E. Cooperative learning in elementary schools. Int. J. Prim. Elem. Early Years Educ. 2015, 43, 5-14. [CrossRef]

37. Cañabate, D.; Martínez, G.; Rodríguez, D.; Colomer, J. Analysing emotions and social skills in physical education. Sustainability 2018, 10, 1585. [CrossRef]

38. Cañabate, D.; Rodriguez, D.; Sánchez, M.L.Z. Physical education and dance: Assessment of inclusion and development in primary schools in Girona province. Apunts Educación Física y Deportes 2016, 125, 53-62. [CrossRef]

39. Frisk, E.; Larson, K.L. Educating for sustainability: Competencies \& practices for transformative action. J. Sustain. Educ. 2011, 2, 2151.

40. Hänze, M.; Berger, R. Cooperative learning, motivational effects, and student characteristics: An experimental study comparing cooperative learning and direct instruction in 12th grade physics classes. Learn. Instr. 2007, 17, 29-41. [CrossRef]

Publisher's Note: MDPI stays neutral with regard to jurisdictional claims in published maps and institutional affiliations.

(C) 2020 by the authors. Licensee MDPI, Basel, Switzerland. This article is an open access article distributed under the terms and conditions of the Creative Commons Attribution (CC BY) license (http://creativecommons.org/licenses/by/4.0/). 